This is a self-archived - parallel published version of this article in the publication archive of the University of Vaasa. It might differ from the original.

\title{
Civil service reform and ethics
}

Author(s): Demmke, Christoph

Title: $\quad$ Civil service reform and ethics

Year: $\quad 2019$

Version: Accepted manuscript

Copyright (C)2019 Springer Nature Switzerland AG. This is a post-peerreview, pre-copyedit version of an article published in Farazmand A. (ed), Global encyclopedia of public administration, public policy, and governance. The final authenticated version is available online at: https://doi.org/10.1007/978-3-319-31816-5.

\section{Please cite the original version:}

Demmke, C., (2019). Civil service reform and ethics. In: Farazmand A. (ed), Global encyclopedia of public administration, public policy, and governance. Springer, Cham. https://doi.org/10.1007/978-3-319-31816-5 


\title{
Governance, HR reforms and Ethics
}

\author{
Christoph Demmke \\ published in: Global Encyclopedia of Public Administration, Public Policy, and Governance, \\ Springer, 2019
}

\section{Keywords}

governance, destandardization, ethical leadership, HR reforms, workplace behaviour

\section{Synonyms}

public administration reform, civil services, HR reforms, ethics

\section{Definition}

Evaluation of how morality and ethics are represented in the discourse about the reform of human resource management and in the context of new governance reforms

\section{Introduction}

Public administration and public HR policies are constituent parts of the system of government. As history shows, countries may survive without government but not without public administration. Until today, no government has completely privatized the delivery of public tasks, no public administration works like a private company and no public HR systems has been totally aligned to private sector practices.

Despite its many specific features and importance for millions of people, the nature of public administrations and HR policies are not well known to the wider public. Moreover, public administration and HR policies as such rarely enjoy a high reputation. At best, public administration reform is an interesting subject for experts. Civil service reforms are mostly dealt with by lawyers, HR specialists and civil servants themselves. It is often seen as managerialist and technocratic. This is strange, as public administration and civil services should serve the public interest and citizenry and therefore, public administration reform should be of great interest to the wider public. Moreover, the very idea of civil service and HR reform raises ethical considerations (Greenwood, 2002; Greenwood, 2013; Budd \& Scoville, 2005)). HR Managers change, shape, 
direct and alter employee's lives. Managers make hiring decisions, assess competences, skills and performance, decide on training needs, rewards, sanctions promotions, telework-opportunity, diversity issues, dismissals, private-work balance, provide feedback etc. All of these tasks have important ethical consequences for individuals.

At the same time, people have high expectations and request that the delivery of public tasks follows ambitious objectives and ethical imperatives. They want employment systems that guarantee observation of the fundamental values, administrative law principles and ensure a focus on effectiveness, efficiency and accountability. Government policies should also ensure equal treatment and fairness, be attractive and competitive with respect to the private sector policies while managing tax payers' money as prudently and while also rewarding individual performance. Increasingly, employment structures should also be diversified and representative while ensuring the merit principle, the equality of chances and the principle of non-discrimination (which is being defined much broader than decades ago).

Thus, people want high performing public administrations that deliver public value in an ethical context. Still, ethics and integrity policies will never achieve a state of perfect integrity. Values as such are ambivalent, conflict with each other and public employees are faced with many dilemmas. Past experience also shows that public management reforms always produce paradoxical and unintentional reform effects and operate in a context of changing values and value conflicts. Therefore, in most cases, ethics policies can only fill the gaps that other policies and system logics produce. On the other hand, ethics should not be a 'plug-in policy' that fills the gaps that other policies and other governance logics produce. It is also time to acknowledge that ethics is not only an abstract and soft-issue. Instead, it is a practical, daily-life issue that is everywhere. However, neither a 'bit of integrity' should be an objective. On the other hand, requiring a state of full integrity is also unrealistic (apart from the question how to define what is full integrity).

\section{Definition of Governance and Ethics}

Governance has become a popular if not trendy concept in the discussions about the changing nature of the state, its role, functions and capacities. It can also be used as a normative concept which prescribes the way in which the State performs. On the other hand, governance can be defined as a theory of change from government to governance. According to Peters and Pierre (2016, vii), Governance is the most commonly utilized term in political science and used in a variety of different, and even contradictory ways. Overall, governance is a descriptive-analytical concept which characterizes the way in which a state, government or other public actors decide, regulate, manage, administer and/or exercise responsibilities and powers. Whereas most observers interpret developments as a shift in the locus of political power from government to networks and other forms of exchange between the state and society, others believe that the state remains very much at the center of governance. Because of its conceptual vagueness, governance research in all 
its forms is highly complex, fragmented and bridging the different scientific disciplines and within the political sciences.

Theories of ethics refer to what is right or wrong, good or bad. Often, the terms ethics and moral are commonly used as interchangeable synonyms. Others, however, define moral as referring to the principles of right and wrong, and ethics as the study of those principles (Huberts 2014, 5).

\section{The traditional link between Government, personnel administration and ethics}

For a long time, personnel administration happened in some form or another. HRM functions such as of hiring, training, compensation, and discipline/ termination were not performed by HR specialists or HR departments. In fact, traditional HRM was rather HR administration and a technical duty within organizations. HR administration was subordinated to "the emergence of the doctrine and practice of scientific management (SM). The first professional/scientific writings on business organization and management appeared in the early 1880s in the United States, authored primarily by engineers. The engineers sought to use principles of science to increase the efficiency of business production systems. Inevitably they were led to consider the 'people' side of production, including methods of employee selection, job assignment, supervision, work pace, and compensation. This new approach found its most influential and strategic formulation in the writings of Frederick Taylor, particularly his book Principles of Scientific Management (1911). Personnel administration was about recruiting people, paying people, sanctioning, controlling and dismissing people.

Thus, personnel administration was about extrinsic motivators. Ethics did not play a role for both sides, employers and employees.

However, gradually, the notion and (ethical) importance of HR administration changed with the birth of HRM (the Hawthorne Experiments) and-later - the further elaboration of motivation theories and the birth of performance management. From now on, HRM grew in complexity.

Before we will come back on this, we need to consider what has changed and how this relates to ethics.

For a long time, it was relatively easy to define the ethical link between Government and the people who served government, the civil servants. In all countries the civil service status was linked to the state as a sovereign power and the rule of law doctrine as well as to the principle of legality. The question who should be given a civil service status was always linked to the task of exercising national public powers, safeguarding the general interest of the state and a traditional nation-state philosophy. This important link between civil service and nation-state can best be observed in the public law status which originates in France aiming to establish and guarantee a democratic state based on the principles of the French Revolution. In Germany, the introduction of the public law status was inspired by philosopher Friedrich Hegel in his Elements of the Philosophy of Right. Hegel's idea of the civil servant and the state as such was conceptualized as a Leviathan (Thomas Hobbes) which stood above the national society and citizens. Its main role was to protect the 
society by enforcing regulations to achieve fairness and to balance the diverging egoistic interests within the society.

In fact, in Europe the emergence of independent and impartial civil services is also closely linked to the emergence of the Republican State (firstly in France) and the Nation-State (especially after the Congress in Vienna in 1815). This strong traditional link between the civil service and the (republican) nation-state has endured in many countries until today. In France, the public law status was "invented" during the French Revolution in order to link the civil servants to the State and not to the Monarchy or other individual interests. Therefore, Bekke/van der Meer (2001) define modern civil service systems as depersonalised systems which differ from traditional modes of government. However, the realization of an independent, impartial and merit - based civil service was more difficult than expected. "Indeed, for much of the nineteenth century (...) the spoils system dominated personnel policy. (...) Public office was perverted into a private fiefdom as arrogance, greed, and opportunism prevailed over honor, openness and prudence. Favoritism, cronyism, intimidation, corruption, waste, scandals and rampant dismissals were widespread in that squalid era. Rather than governance; its highest priority was to reward its friends, to grant favors for favors given" (Bowman/West 2008, 183).

In the $19^{\text {th }}$ century, the biggest changes included the introduction of centralized recruitment procedures, the adoption of civil service laws, the centralization of HR policies and the introduction of merit principles (including entrance examinations, job tenure, career service, political neutrality) which were adopted - as a moral guardian to democracy - and which should shield employees from politically inspired employment actions. "Instrumental in effectuating these changes was the establishment of the Rechtsstaat or in Anglo-Saxon terms the rule of law (...). This powerful idea had implications for the relation between government and the civil service system. (...) Step by step the legal position of civil servants in all countries was formalised and standardised (...). Merit instead of privilege was becoming the guiding principle" (Bekke van der Meer 2001, 278). The status of the civil servants evolved into a protected status with many specific employment features that differed to ordinary employment patterns. Contrary to this, the purpose of creating a modern civil service was a response to the emergence of the liberal state which was based on the rule of law. Consequently, almost all Member States designed their public organizations in specific ways because they expected a certain behavior on the part of civil servants would result from specific organizational features.

In the $20^{\text {th }}$ century, countries introduced hierarchical and formalized organizational structures, scientific management methods (according to Taylor and Fayol) clear and rigid career paths, lifetime tenure, full-time employment, seniority, advantageous pension systems and rigid remuneration systems were introduced in order to reduce as far as possible the risk of too much political influence, corruption, misconduct, the exercise of private interests and instability of government. Until today, the essence of administrative behavior is to follow hierarchical principles and doctrines which are based on the rule of law. Following this, at a minimal level, administration is considered to be good and ethical if it achieves the implementation and enforcement of the existing laws and policy goals of the Government of the day. Moreover, ethically good or 
acceptable behavior is also still defined in terms of rationality, law obedience, impartiality and standardization. From the ethical point of view following law or superior's orders is usually not problematic. It is still a very relevant guideline for public officials, as it highlights the importance of the rule of law and loyalty to democratically elected government.

Dicey expressed the meaning in this way: "when we speak of the "rule of law" as a characteristic of our country, not only that with us no man is above the law, but (which is a different thing) that, every man, whatever his rank or condition, is subject to the ordinary law of the realm and amendable to the jurisdiction of the ordinary tribunals. Thus no one is above the law, and all are subject to the same law administered in the same courts" (Bingham 2010, 4). This principle was translated into concrete HR policies.

When looking back, the traditional argument for a specific organizational structure and specific HR policies were to produce a certain ethical status for civil servants who should be committed to the public good, neutrality, impartiality and to observing confidentiality and displaying expertise. In many countries, therefore, civil servants were working in hierarchical organizations, had very specific recruitment procedures, specific ethical obligations, little mobility, varying working conditions and specific social security systems. Many experts were convinced that these specific organizational structures and employment conditions "produce" a certain public service ethos, individual performance and "public service motivation" for civil servants who - in exchange - are committed to the public good, neutrality, impartiality and to observing confidentiality and displaying expertise.

Until today, this traditional rational, technical and instrumental understanding of Fordism, Taylorism and bureaucracy and of "organizations" and of "people" have not completely vanished. With central public administrations still being closed off and separated from society and citizens, central public employees are still a relatively protected category of staff. Because of their still existing specific treatment, civil servants are supposed to have a specific Public Service Motivation (PSM), having different values and different personalities, being motivated by different incentives, working differently than employees in the private sector, being more security-minded, performing differently, being more rule-oriented and more oriented to the common good.

\section{Why countries started to deviate from the traditional government models}

In all countries, civil service concepts were designed with the objective to make the public sector independent from the private sector and civil servants independent from personal interests. For these tasks and duties many countries were reluctant to outsource or to privatize core governmental tasks and to completely reverse established specific employment features and HR policies that were founded in the $19^{\text {th }}$ century in order to protect the democratic and liberal state. In most cases civil services were designed as rational machines which had a democratic and ethical function, and which should serve the society and the law, protect the population, act in not discriminatory ways as well as function in a sustainable manner. When looking back, this traditional technical, legalistic 
and bureaucratic compliance and ethics of neutrality (Thompson 1985) approach has dominated within government until at least the 1970's.

However, increasingly, almost all countries started to deviate from the classical bureaucratic model and introduced changes which led to a new diversity of administrative systems. Today, debureaucratization trends continue but there is no common trend towards an alternative universal administrative model. Rather, current reform modes are caught in an identity crisis. Countries know well what they want to leave behind. But they do not know where to go. Consequently, there is also no trend towards a best-practice model.

Therefore, there is only broad acceptance that the times of bureaucratic career models are over because these concepts underperformed on several fronts:

- Bureaucratic structures were built on the assumption that public management differs to private sector management and public values should be safeguarded against private sector values. In fact, de Graaf and van de Wal show that that "the values of profitability, competitiveness, and customer orientation have a greater influence on business decisions; in public organisations, values such as legitimacy, lawfulness, accountability, and impartiality play a larger role. However, great differences exist among the organisations within each sector" (de Graaf/van der Wal 2008, 79). However, values overlap in public and private sector organisations. Thus, empirical research shows that public and private value patterns cannot be clearly distinguished, and many organizational values appear to be shared among government and business managers. Thus, similarities exceed differences. Still, it must be examined whether a correlation exists between certain sector specific values intermixing between both sectors and certain specific moral and functional problems, especially in semipublic and hybrid organizations (Van der Wal, Z./Huberts, L./Van den Heuvel, H./Kolthoff, E. 2007). Hence, artificial distinctions between public and private values are not needed anymore in times of "blurring of boundaries between the public and private sector". For example, 'common core' values are accountability, expertise, reliability, efficiency and effectiveness, all of which are considered crucial in both public and private sector organizations. Additional analysis seems to suggest that value preferences are primarily attached to sector rather than to age, gender, working experience, or previous employment in the other sector

- The concept of bureaucracy was built under the premise that the political, administrative and public spheres should be separated. Today, a blurring of boundaries takes place between international politics and national politics, private and public tasks, civil services and private sector employment, work and private life, rationality and irrationality and between many other spheres which were supposed to be separated. This blurring of boundaries is quite ironic as many traditional tasks and duties of the national civil services are not changing. However, these trends make it more difficult to legitimate an elitist civil service, which enjoy different employment and working conditions than other employees. 
- Traditional bureaucratic (HR) administration is under attack particularly because of its long time focus on bureaucratic, standardized approaches and technical HR issues such as recruitment, selection, payroll, benefits, employee relations, performance management, industrial relations, legal issues and its limited role in achieving business objectives. Today, its core claims and professional self-image have become entwined with behavioral, psychological, ethical, financial, budgetary and managerial narratives (Thompson 2011, 363). Overall, organizational structures, the acceptance of rationality as a principle, the understanding of role and importance of HRM, motivation- and leadership theories have enormously developed since the publication of the Hawthorne Experiments and - later developments in the neurosciences.

- Another problem with the concept of bureaucracy and civil service is, because as an ethical guideline, it is simply too narrow for today's multi-level governance. Especially the importance of individuals was neglected because of the focus on the concept of "administrative neutrality" and the dominance of rational and legal approaches. Insights from behavioral economy and motivation theory have indeed shown that work in the public sector is more value-laden and more unpredictable than ever. On the other hand, allowing new behavioral insights and organizational psychology to play a more important role in civil service systems may also open the box to very uncertain future developments. For example, wwhereas traditional writers such as Wilson, Weber and Taylor believed that rationality should be the guiding principle of any civil service system, today, the term bounded rationality (Simon) has become a buzz word and new behavioral insights and behavioral instruments such as nudging have become a new fashion. Overall, civil serviceand HR-reforms are increasingly influenced by the "psychologication of HRM". We will come back to this.

- Next, role and importance of fairness perceptions, the importance of individual recognition and emotions at the workplace was never recognized in the traditional public sector. In the meantime, theories of diversity, recognition, engagement and organisational justice are central in explaining counterproductive work behavior. New evidence suggests that there is differential relationship between different types of justice (perceptions) and counterproductive work behavior. Moreover, emotions are a bridge between justice perceptions and behavioural responses (Moliner et al. 2017)). Overall, justice perceptions depend on personal traits such as attitudes, status, expertise, experience and leadership style.

- Elsewhere, change is also explained by dysfunctions of the classical bureaucratic model which is/was too costly, discriminatory, too rigid, too hierarchical, not innovative, not performing well enough and causing de-motivating effects. Often, it is claimed that new organizational models are needed (whatever type of models these are) to render public services superior, more flexible, innovative, effective, efficient and outcome oriented. Increasingly, evidence from organizational science demonstrate that bureaucratic and 
hierarchical structures do not perform better than other organizational types (as suggested by Max Weber one hundred years ago).

- Until today, there is no evidence that bureaucratic structures produce the intended results. Evidence is growing that specific public working conditions and bureaucratic structures do not necessarily produce less corruption and a specific public service ethos. Dahlström and Lapuente (Dahlström/Lapuente 2017) examine the existing link between bureaucratic structures and corruption. Both authors also conclude that closed bureaucracies are negatively related to the quality of governance .In "The Merit of Meritocratization: Politics, Bureaucracy, and the Institutional Deterrents of Corruption" Dahlström et al (Dahlström et al. 2012; see also Rauch 2000) concluded that only some bureaucratic factors (most notably the meritocratic recruitment of public employees) exert a significant influence on curbing corruption even when controlling for the impact of most standard political variables. In her study on the Quest for Good Governance Mungiu-Pippidi (2016, $21,29)$ ) concludes that countries with a higher power-distance culture have higher levels of corruption. On the other hand, one explanatory variable for high levels of corruption is also the blurring of boundaries between the public and the private sector. The latter also applies to those more private-sector like countries with an open access order ${ }^{1}$. MeyerSahling et al. (2016) and Kopecky et al (2016) examine patronage and politicisation trends in central and eastern Europe and on the western Balkan. However, also in western Europe, politicisation is rising - again.

Still, Government and traditional bureaucratic features are not disappearing. Contrary to this: In some cases, trends seem to be towards the revival of the "Leviathan" concepts and flexible ways of governance that combine forms of hierarchical steering and participative modes of steering. Thus, the current paradox is that, despite all changes that are leading to the "blurring of the state" and ever new statements and conclusions about the emergence of ever new Governance-like and networking-type structures, "Government" still exists, and the state is not powerless. Also, state capitalism does not disappear. In public policies, classical public tasks such as "security", "education" and "skill development" have become top-issues on the political agenda. Also, the reactions to the financial crash in 2008 and numerous bails out policies, the hierarchical management of the Greek financial crisis, the management of the refugee crisis and state responses to numerous terrorist attacks and (supposed) security threats everywhere in the world have demonstrated that "Leviathan" is not dead. Although the boundaries between the civil services and the societies are further eroding, the strong state has even re-appeared in many public policies, for example in the fight against terrorism, cyber-crime, security issues, data protection etc.

\footnotetext{
${ }^{1}$ Mungiu-Pippidi distinguishes between Governance regimes with a limited access order and an open access order and believes that the latter countries have a sharper separation between the public and the private sector, p. 29.
} 
As understandable some of these trends are, they also illustrate the ongoing need to protect the rule of law, privacy, individual freedom, the need to Government and offer protection for citizens against arbitrary state- and administrative decisions.

These trends lead us to the following questions: If some traditional features of the traditional state, public administration and civil services are re-emerging but other classical features are slowly disappearing, how will the new civil services look like? What is the impact on the above-mentioned changes on the principle of democracy, merit, rule of law and the importance of values as such? Do we live a revival of a traditional pre-modern "Leviathan-like civil service conception" combined with a post-modern digitalized and individualized work system?

\section{The nature of change and the implications for the national civil services}

According to neo-institutional theories, the political and institutional world is currently moving away from universal or even best-practice institutional configurations towards more specific bestfit context-related models. New developments lean more towards the testing of new organisational models and work systems that fit into the national, regional, local or even organisational and leader-follower context. Best fit schools are associated with this contingency approach and argue that organizations must adapt their strategies and implement reforms to the specific local strategy and to its environment.

Also, in the field of institutionalization ethics management, the effectiveness of any particular ethics infrastructure system is determined by the degree of consistency amongst its constituent elements and the way they fit into the organisation, HR policies, culture and leadership styles. According to Huberts (2014), it is only possible to stress the 'basics of an integrity system' (Huberts 2014, 190) because working conditions, leadership styles and work organisations continue to differ, ranging from traditional Taylorism models to high-involvement or high-job autonomy models with low hierarchies and high levels of job autonomy. Also, the role of employee management varies from very paternalistic to very communicative and partnershiporiented forms (of social dialogue). Consequently, there is no bureaucratic one-size-fits-all organizational model anymore: Instead, trends are towards multiple forms of organizational structures, ranging from traditional and bureaucratic working systems to innovative workplaces and learning organizations within different governmental organisations and even within the same organizations.

In fact, there can have been few times when it has been a greater challenge to understand the changing nature of the national public administrations and the impact on ethics and workplace behavior - worldwide. Classical typologies like career-systems, position-systems, or closed bureaucracies belong to the past. Overall, public employment is changing about the size, structure, composition and status. The national central public administrations are becoming more flexible, diverse, feminine, fragmented and smaller. All countries are eager to enhance efficiency, productivity and innovation by cutting budgets although there is no best-practice blueprint how to do this without the loss of other values and the emergence of new value conflicts. Today, most

experts believe that trends in organizational reform are towards a move to non-Taylorism learning 
work organization and agree upon the proposition that new forms of HR strategies and HR practices are associated with superior performance (Eurofound 2009). Increasingly, the design of work systems is linked to organizational learning, innovation and organizational performance. Still, one of the main challenges in the field of organizational theory and HRM is to develop and measure world-wide aggregate measures that can be used to measure the relation between (the change of) work systems, HRM, organizational learning, organizational performance and workplace behavior. So far, empirical work on these links has been carried out mostly by the European Foundation for the Improvement of Living and Working Conditions (Eurofound 2009). Basically, Eurofound has concluded that where work is organized to support high levels of discretion, team working, learning levels and job complexity, in solving complex problems, organizations tend to be better performing and more active in terms of innovation (Eurofound 2009). This again has positive effects on workplace behavior. However, the link between more job autonomy and politicization is less clear.

All current reform trends take place in a context - to use the concept used by Robert Merton - in which purposive action does not imply "rationality" of human action (Merton 1936). This implies that, increasingly, it is accepted that the most important limitation to a correct anticipation of consequences of action is provided by the existing state of limited knowledge in the context of increasing criticism towards classical rational choice theories. Because of this, behavioral economics have grown in importance and have increasingly informed politics, both in the private and in the public sector. Today, Thaler and Sunstein (Thaler\& Sunstein 2008) are enthusiastic about libertarian paternalist nudging in the private and in the public sector because they are impressed by the imperfection in individual decision-making and the low costs of nudging. They catalogue many factors that can lead to mistakes in human judgment and decision-making such as optimism, overconfidence, loss aversion, s status quo bias, framing, inertia, inattention and error etc.

In the meantime, modern public officials have more individual decision-making discretion than ever before. They are also better educated than ever. they also enjoy more job autonomy. However, this post-bureaucratic trend towards more job autonomy comes with strings attached. For example, more job autonomy and individual responsibility is also related to more stress and job intensity. Next, trends towards self-responsibilisation and the growing importance of intrinsic motivators sometimes take forms of exploiting employees (Guest 2012, 55).

Again, numerous studies have also demonstrated that specific types of organizations that focus on job autonomy, learning opportunities and team-work have better operational and financial performance through enhanced intermediate outcomes such as increased job satisfaction and productivity and reduced turnover and less absenteeism. Current research in the field of organizational behavior is interested in exploring how employees' perceptions of organizational structures, HR policies and leadership influence their work-related thoughts and behaviors and how transformational and transactional leadership supports organizational performance. Also, literature on engaging employees has become popular and advocates the link between engagement levels and organizational performance. The latter is the more interesting as different engagement 
levels seem to correlate with individual performance, organizational performance and levels of innovation. There is also an emphasis on engagement that encourages, and rewards learning and is positively linked to organizational performance. However, the level of engagement is depending on many variables such as the design of the work organization, leadership, work environment, working conditions and the psychological contract between the employee and the employer.

Employees that rate their work organization, the support of their leaders, the work environment and the psychological contract high, have significant better results in work engagement as well. Still, the literature on the importance of job engagement is far from conclusive and, even, skeptical, as the concept as such operates in "different worlds" (Guest 2014) and is concerned either with employee well-being or with organizational performance. Purcell (2014) argues that the concept lacks a contextual understanding and that the concept of engagement pictures a person "so engrossed in work that it can only ever apply to a minority of employees" (Purcell 2014, 242). This again leads to a negative view of employees who are not fully engaged and a psychologizing of employment relations where problems of motivation and "engagement" can easily be attributed to individual phenomena. "This is a dangerous reduction of work relations to individual attributes and failings" (Purcell 2014, 244). There is a clear danger that, increasingly, employees who are not fully engaged are described in negative terms implying this is their own fault... (Purcell 2014, 245). Self-efficacy theory explains why employees want to be engaged and committed. People with a strong sense of efficacy approach difficult tasks as challenges and are motivated through engagement. Consequently, employers want engaged employees, too. However, as already discussed, this "ideal combination" leads to s situation, where employers exploit their "engaged" employees without exchanges, for example about offering decent work conditions.

\section{Towards the end of bureaucracy, bureaucracy - lite, or the return to leviathan?}

Looking into the relationship of Governance reforms, HR policies and ethics is a daunting task. Today, experts hugely differ as regards the future of governance. For example, whereas some observers predict the total marketization of societies and public policies, others observe trends towards a sharing public sector and economy, others discuss the emergence of block chaining as the new reform fashion and - again others - predicts the return of the strong state, Leviathan, as security issues become ever more dominant in our societies. Again, another group observes trends towards a further professionalization of normative concepts like Good Governance and more state interventions in moral politics, or towards more flexible forms of governance which adapt themselves from policy-area to policy-area.

Thus, present governance developments are at least contradictory. From the inside, organizational reform trends are towards more fragmentation, flexibilization, decentralization and individualization. From an HRM point of view, personnel management is no longer treated as a purely technical issue and an exclusive focus on issues such as recruitment, selection, payroll, benefits, employee relations, performance management, industrial relations and legal issues. Instead HRM has become an integral part of management, organisational theory and the behavioural sciences with an interest in all aspects of human life. Moreover, digitalization and 
flexibilization trends are changing work systems and leading to an individualization of HR practices by facilitating the monitoring, measuring and recording of individual efforts and engagement practices.

Also, the field of civil service reform is subject of great speculation. Whereas in the past public administration and civil service reform was the preserve of legal scholars, today it is dealt with in management science, organizational theory, behavioral economy, leadership theory, organizational justice, motivation theory, social analysis of human interaction, organizational behavior and law. Overall, public administration- and HR reform- as academic disciplines - have grown in complexity. This mostly concerns the development of motivation theory, leadership theories, the link between HRM and organizational performance and new evidence in the field of social dialogue, participation and voice. Thus, public HRM tries to distance itself from its stuffy, technical and traditional mechanical image and confirms its significance for corporate profitability, performance and innovation (Pinnington/Macklin/Campbell 2007) while balancing different employee's and employer's interest with the need for change, adaptability, discipline and stability. In fact, today, most Governments shy away, through law, politics and the implementation of Public management reform measures to impose any particular (bureaucratic) conception of a specific public service organizational and employment structure that differs to private sector practices. As it seems, national civil services are moving towards the emergence of a new sort of mixture between the revival of "Leviathan" concepts and blurred, decentralized, fragmented and psychologized types of civil services. This makes it also difficult to say whether some aspects of the bureaucratic paradigm will survive or whether we experience the beginning of a new postbureaucratic, high performance work system paradigm, which is based on individualized HR management. For example, despite the popularity to criticize the over-emphasis on laws and rules in contemporary civil services, the primacy of law is - vital - and will (hopefully) remain in the future.

Whatever will be the case, the classical bureaucracies are about to change. It is not yet clear what the post-bureaucratic paradigm is, apart from remedies to the weaknesses of the classical bureaucratic model. Still, developments like decentralization, responsibilities, flexibilization, skill development, engagement, mobility etc. are too wide and too fluid concepts. These developments are also full of paradoxes and ambivalences. Consequently, they represent alternatives to the classical models. But do this also mean improvement?

Still, it is also far too early to predict the end of the bureaucratic model: Too often, popular public management reform is influenced by trendy management advisers who often spin an unrealistic yarn about administration by giving the impression that hierarchic and bureaucratic administrative structures have long since ceased to exist. Despite trends towards more individual job autonomy and responsibilities, almost all administrative models also continue to be based on the principle of 'hierarchy' and bureaucracy. An empirical study by Vie (2010) concludes that post-bureaucracy is "only a language construction that has little impact on everyday practice in organizations. Especially the proclamation of a general downfall of hierarchic structure in organizations stands in sharp contrast to the empirical reality" (Vie 2010). In fact, reported radical breaks from the past 
are exaggerated. In reality, new elements of work practices are gaining ground without replacing old ways (Vie 2010, 191). Vie concludes that the work practices of top-managers change faster than of middle managers who are still preoccupied with administrative routine and bureaucratic control.

What is sure is that contemporary central public administrations are increasingly complex and fragmented. In the future, they will most likely become more complicated and probably more contradictory all the time. Consequently, value conflicts are increasing, too. What are the implications on ethics and workplace behavior?

New societal trends towards individualization, informalization, digitalization, globalization and intensification of work produce new forms of ethical challenges for Government. Overall, it seems that new types of work systems also produce new dilemmas and paradoxes, such as enhanced job intensity and stress levels. This also suggests that the current departure from rational and hierarchical types of (bureaucratic) organizations will also bring new, so far, unknown challenges. In "The Responsible Administrator" Cooper argues that "we are in a time of transition in which the modern heritage of public administration is increasingly in conflict with a postmodern model" (Cooper 2006, 45). The key phenomena of modernity are assumptions about universal values, absolute values, bureaucracy and rationality. Contrary to this postmodern is a term in which "fundamental assumptions are being discredited as final and absolute. Assumptions about objectively real and universal human nature, or natural law, or absolute values and ultimate truths (...) no longer hold..." (Cooper, 2006, 46)). "The homogeneity of traditional society, with its unifying and stabilizing cultural bonds, has been broken. (...). New forms of lifestyles have developed, and new ways of coping with a broad spectrum of lifestyles, diets, preferences, political philosophies, and modes of exchange have evolved" (Cooper, 2006, 52).

The implication of these changes for public administration are obvious: Today's public administrations tend to be much more diverse, less hierarchical, more flexible, diverse, representative and less separated from the citizenry. Whereas the term bureaucracy represented clear values ("hierarchy, formalism, standardisation, rationality, obedience etc.), new reforms bring new values, but also more conflicting values and value dilemmas.

Thus, the problem with this description of the administration in the $21^{\text {st }}$ century is obvious. Whereas the term "bureaucracy" or "modernity" can be defined and broken down into concrete contents, this is much less the case with the definition of new systems and new administrative models. Although the terms post-Weberian models or post bureaucracy may be adequate descriptions of the current change processes, these concepts leave those who oversee introducing change processes puzzled. Overall, we do not only lack an understanding of what could be an (universal) alternative to the bureaucratic form of organisation.

Instead, what is also missing is a better understanding how ethics change in the context of Governance-, organizational and HR changes. So far, discussions have focused on the link between public management reforms and ethics but to a much lesser degree on the effects of civil serviceand HR reforms. Academic discussions are still very rudimentary. 
As of the 1990's, experts started to call for an alternative to the bureaucratic 'compliance-based' ethics model, the so-called 'value based' model. In the beginning, discussions on this alternative model were highly influential and successful. Many countries started to move away from legal and top-down approaches. For a number of years, changes had been in progress. However, since a number of years, reforms do not indicate convergence towards a new value-based model. Let us take a step back to look at these interesting trends.

According to Weber, the essence of administrative behavior is to follow legally given orders. Following this, at a minimal level, administration was good and ethical if it achieved the implementation and enforcement of the existing laws and policy goals of the government of the day. Moreover, ethically good or acceptable behavior was also defined in terms of obedience to the law, impartiality and standardization. The purpose of rule-orientation was also to achieve fairness and equity, to implement the merit principle, to allocate rights to citizens and to protect public employees against arbitrary administrative decisions. Thus, 'the ethics of neutrality and structure' (Thompson, 1985, 555-561) is the cornerstone of the traditional bureaucracy. From the ethical point of view, following the law or the superior's orders is usually not problematic, if obedience and excessive adherence to rules do not become absolute values. ${ }^{2}$

However, the problem with the Weberian concept is that as an ethical guideline it is simply too narrow for today's multi-level governance. As already discussed, work in the public sphere is much more complex, digitalized, fragmented, individualized and no longer dominated by the principles as Weber predicted. On the other hand, some traditional principles such as the rule of law and administrative law as such remain the core principles of all administrative systems. However, with the emergence of NPM euphoria, administrative law was mostly seen as a constraint that blocks policy choices, innovation and reform policies. Traditional administrative behavior was held to be rigid, rulebound, centralized and obsessed with dictating how things should be done - regulating the process, controlling the inputs - but totally ignoring the end results. Consequently, NPM theories dominated from the 1990s onwards and the compliance approach was old-fashioned and ineffective. Suddenly, the focus was on codes of ethics, training, leadership, decentralization, delegation and flexibility, instead of on law. As a result, discussions focused on the adoption of new digital, soft, informal and managerial approaches and a call to move away from regulatory approaches.

In the meantime, academic discussions have turned away from the 'grand old' dichotomy: valuebased approaches versus compliance-based approaches. This can best be seen in the field of conflicts of interest, where countries have started to realize that the management of conflicts of interest does not work without clear rules, formal procedures, monitoring and strong enforcement mechanisms but also not without awareness raising, strong leadership, independent ethics committees, registers of interest and more and better management capacity. Most 'compliancebased' countries such as Germany no longer focus entirely on rules and trust in the effectiveness of sanctions. However, the focus on both concepts has lost much of its appeal, since the focus on NPM theories (and an excessive focus on rational choice theories and soft-instruments) as much as on classical bureaucratic approaches is in both cases also revealing many negative effects. 
This means that the circle of new ideas and concepts has started again. Here, the focus is no longer on private sector models, or on new soft-managerial models. Instead, it is about the search for more efficiency, effectiveness, quality, better outcomes and citizen-orientation. In fact, it is all about better administration and the ongoing search for new good-governance models in a digital governance context.

These trends show that the increase of complexity of societies correspond with the increase of complexity of ethics as such. Neither the compliance based, nor the value-based approaches give an answer to these developments. Instead, discussions on the best ethics policies, best-practices and effective ethics instruments have become more context-oriented. At the same time, ethics bureaucracies are about to emerge. Overall, ethics policies become more important and countries invest in the institutionalization, monitoring and enforcement of ethics policies. Still, many doubts exist whether these trends enhance the effectiveness of ethics policies, improve trust levels, or just producing ever new forms of integrity paradoxes.

\section{The psychologisation of HRM}

Current trends in HRM have opened public employment for ever more diverse employment innovations. Whereas most governments agree that politics should not try to form the character or cultivate the virtue of its citizens, the increasing popularity of behavioral ethics and affective turns in politics, HRM and in economics and the popularity of nudging (as an instrument), destandardization trends and the trend towards the delegation of own responsibilities to employees through different concepts such as engagement, life-long learning and competency-development (as HRM policies) show that current trends in HR policies are leading towards an individualization and "psychologisation" of HRM (Godard, 2014).

These developments run counter to a grand administrative tradition: For a long time, HRM in the public sector was dominated by rational, legal, standardized and technical approaches. Today, traditional HRM is in trouble, both theoretically and practically because it is challenged by ethical, financial and budgetary, behavioral, managerial narratives and developments in the neurosciences (Thompson 2011, 363). Currently, the discipline of HRM integrates new evidence, especially from the behavioral sciences. This is a reaction to the traditional focus in the field which was based on legal, economic and political ideas that ignored psychological aspects, although evidence existed since the Hawthorne Experiments (and even well before) that individual behavior is largely influenced by justice and fairness perceptions, emotions and feelings, such as hope, fear, aspirations, expectations etc. Instruments such as nudging have become tremendously popular. For example, in the field of ethics, approaches that are based on laws and compliance-based approaches are believed to be ineffective since they guard only against intentional forms of unethical behavior (and not unintentional forms). Disciplines like behavioral ethics explain why people overestimate their ability to do what is right and why they act unethical without meaning to (Bazerman and Tenbrunsel 2011). This turn towards behavioral approaches can be explained because of the shortcomings of traditional (bureaucratic) approaches. However, they are neither new, nor without problems. 
Almost one hundred years ago, Parker Follett argued in The Giving of Orders (1926), you "cannot get people to do things most satisfactorily by ordering them or exhorting them; but also that even reasoning with them, even convincing them intellectually, may not be enough (...). For all our past life, our early training, our later experience, all our emotions, beliefs, prejudices, every desire that we have, have formed certain habits of mind ... Therefore, it will do little good merely to get intellectual agreement; unless you change the habit pattern of people, you have not really changed your people" (Parker Follett 1926).

Some decades later, Lindblom suggested that "decisions within this political setting can never be wholly rational but (...) are of a "bounded rational" nature. That is to say, instead of insisting on an "optimal solution", the public policy maker must be satisfied with what is "good enough", or as Lindbloom suggested: must "muddle through" (Lindblom 1959).

In the $1950^{\text {th }}$ Simon did not deny the possibility of change processes as a result of rational processes. However, he showed that organisations never work purely rationally or perfectly: "We forget sometimes that an organisation is a group of people behaving, These people are not tools or machines. They have feelings, hopes, and fears. They get sick, hungry, angry, frustrated, happy, sad. Their behaviour is subject to a whole range of influences extending back to their births..." (Simon 1973, 55). According to Simon, plays the most important role in the day-to-day work of every organization. Without communication, no steps can be taken toward human cooperation, and it is impossible to speak about organizational problems without speaking about communication. At the root of public administration are continuous conflicts and communication blockages due to

- Barriers of language (misinterpretation and misunderstanding)

- Differing frames of reference (different mental understanding of definitions)

- Geographical distance impeding the communication process (over Units, Countries, Ministries)

- Status distance as a filtering process throughout hierarchical levels of organisation

- Self-protection (individuals tend to communicate more those things that are to their benefit)

- Pressure of work (people tend to overlook important matters)

- Censorship (limitations on the flow of information by authority or force).

Thus, already many years ago experts arrived at the conclusion that, in reality, work in the public sector is paradoxical, individual, value-laden, emotional, pluralistic, political and unpredictable. Weber and Taylor neglected the importance of individuals because of their focus on the concept of "administrative neutrality" and the dominance of rational and legal approaches. There is no place to confront the two approaches and to discuss all pros and cons. In fact, the ultimate measure of any HR system is the quality, efficiency, impartiality, professionalism and responsiveness that it delivers and how it furthers the possibilities to reach and fulfil objectives and helps delivering services of good quality to citizens. New behavioral approaches are to be welcomed if they do not lead to a new "moral relativism" and the revision of rational thinking as such. With the popularity 
of behavioral insights, classical concepts (and instruments) such as the rule of law and principles of administrative law are questioned.

\section{The destandardization and individualisation of HRM}

As discussed, the key phenomena of modernity were assumptions about universal values, absolute values, bureaucracy and rationality. Contrary to this, present reform trends discredit universal and absolute assumptions (Cooper 2006, 45). According to Fukuyama (2018), universal concepts are being challenged by partial forms of recognition based on nation, religion, sect, race, ethnicity, or gender, or by individuals wanting to be recognized as superior. "The rise of identity politics in modern liberal democracies is one of the chief threats that they face..." (Fukuyama, 2018, xvi). Also, in the field of public management, the era in which treating all persons in the same way meant treating everybody fairly is not anymore the paradigm of our times. Consequently, theories on organizational justice are gaining in importance and HR administrators and line managers need to rethink how to measure performance and to treat people unequally and yet to be fair (Karam et al., 2019). Therefore, a new challenge is to design fair HR systems under decentralized and individualized conditions, ,the challenge in the longer run ....is to design organizations that combine the efficiency and service capacity of decentralized organizations with the uniform and legalistic nature of hierarchical organizations" (Peters and Pierre 2003,6)

In the field of HRM, destandardization, diversity and individualization reforms have been introduced in a wide range of HR policies and HR structures. This concern the:

- destandardization and flexibilization of working time,

- destandardization and individualisation in pay (through trends towards the differentiation of pay and performance related-pay),

- destandardization of recruitment methods and procedures which were based on qualifications and not on skill development and competencies,

- destandardization and individualisation of training, e.g. coaching and career development policies,

- destandardization and individualisation of skill development and competency management policies,

- flexibilization of retirement policies and retirement ages,

- flexibilization of contracts and employment policies,

- introduction of diversity policies,

- decentralisation of HR competences to line managers,

- reform of the organisation of work and provisions for more job autonomy,

- the possibility for more public-private, interministerial, intraministerial and intra-careermobility,

- the abolishment of traditional career progression policies such as automatic seniority progression. 
All these developments create new opportunities, but also new challenges. For example, destandardization trends have arguably placed the morality of legal approaches and standardized and merit-based HRM practices increasingly in the hand of managers, line managers and HR experts who have discretion and decision-making powers in these fields (Bezes \& Jeannot, 2018). The decline of standardized approaches has left many employees more vulnerable to individual discretionary, opportunistic and subjective behavior. This throws more into question "the morality of contemporary HRM and increases the significance of engaging in moral evaluation of the behavior of directors, managers and HR practitioners" (Pinnington/Macklin/Campbell 2012, 3). On the other hand, these trends towards destandardization of HR practices, visions on self-reliant individuals and trends in the field of individual competency and skill policies also challenge classical merit-based concepts. How to maintain merit, fairness and equal treatment in a fragmented, decentralized and individualized context? In former times, HR policies were based on the principle that everybody should be treated in the same way in order to be fair.

a. The destandardization of remuneration and fairness perceptions

For a long time, civil servants in the same age cohort, with the same rank and the same qualification were paid the same salary (which, often, was increased regularly in conformity with the principle of seniority and automatic pay progression). Traditional remuneration systems were established decades ago and for a long time they changed very little. The traditional focus on careers, stability, seniority and positions made sense when the vast majority in the public service had similar qualifications and jobs. The classical pay system was adapted to the dominant values at the time: bureaucratization, standardization and equality. Thus, whereas public pay systems were based on the principle of equality, private sector pay systems were based on the principle of autonomy Today, the era in which treating everybody the same meant treating everybody fairly is not anymore the paradigm of our times. Today, most people believe that everybody should be treated equally but also differently in order to be fair (Cooper 2006, 53).

Consequently, traditional pay systems with their career ladders, time-based pay increases and specific allowances are increasingly reflecting a slowly disappearing concept of employment. That model was designed to reward loyalty by providing high levels of job security. Today, employees themselves expect immediate rewards and recognition for their individual accomplishments. So far, little research has been carried out on the impact of destandardization trends and the change of merit-based approaches on workplace behavior and perceptions of organizational justice (amongst employees). Overall, pay diversity as such has increased within the national systems and amongst the different occupations and ranks. Also, the structure of the systems has become more diverse. For example, today it is perceived as fair if civil servants earn higher salaries if he/she demonstrates outstanding performance and receives positive performance evaluations. However, this logic also leads to the question whether and how professional and fair performance assessment are possible at all is possible at all that justifies unequal pay. This trend towards pay dispersion creates problems if managers fail to increase employees' perception of legitimacy of pay dispersion 
(and organizational fairness perceptions), which suggests that procedural fairness of the HR systems can maximize the effectiveness of distribution of organizational resources, such as pay.

Public employees constantly compare their performance with the performance of their colleagues (Note: and mostly believe that they are better than others). Often, employees believe that their pay is not fair since they perform better than their colleagues. Many also believe that their performance is not managed, assessed and measured in a professional way. Consequently, fairness perceptions have changed and differ from the past. From now on, new feelings of being treated unfairly (for example by those who measure performance levels) emerge and, in many instances, people are even more demotivated and frustrated after the introduction of PRP. Since people constantly compare themselves with other colleagues, they also tend to believe that colleagues who receive bonuses and PRP do not deserve them. Often, employees who do not receive PRP may also be demotivated since they expected to get bonuses etc. Another dilemma concerns the fact that many employees do not trust their superiors to take fair decisions on the allocation of PRP. Consequently, many people feel that they are treated unfairly because of unprofessional or unfair pay decisions of their superiors. In all these cases, the expectation to be treated individually conflicts with the expectation to be treated equally. As it seems, the individualization of pay and growing differences in pay also produce higher levels of perceptions of distributional injustice.

However, exactly because of the ongoing individualization trends, people are increasingly attentive to the justice of events and situations in their everyday lives across a variety of contexts. Increasingly, individuals react to actions and decisions made by organizations every day). Consequently, perceptions of unjust and unfair treatment can strongly influence the individual behavior and may exert a good or bad impact on individual and organizational performance.

b. The destandardization of recruitment policies and fairness

In the past, national civil services always used common and standardized recruitment frameworks (such as concours). Overall, people were recruited based on qualification (and diplomas). Most countries also installed merit-based recruitment systems that set common standards for civil servants to meet through, for example, standardized testing. These systems were designed to ensure a high degree of professionalization (as opposed to politicization) of the civil service, and to ensure that all applicants are provided with equal opportunities. While such systems responded to values of internal equity, professionalism and equal access, they were criticized because they underperformed in a context of competition for particular skill sets (OECD 2017c, 75). Moreover, they underperform because they are based on skills and qualifications (ratings) that were achieved (and evaluated) in the past and not on the development of new (social and technical) skills and (soft) competences. Today, politicians and managers repeat the mantra that economic competitiveness depend crucially on the skills and investments in training of the workforce. Everywhere, governments, politicians and management experts agree upon the key role that skills, training and long-life-learning play in securing competitiveness and social-cohesion. Within this discourse, it seems that skills are the answer to a whole set of economic and social problems. With 
the increasing importance of skill policies, also the notion of skills has also become considerably broader than it was in the past. Today, the popular skill discourse uses very different notions like enlarging basic skills, employability skills, adapting skills, key skills, management skills, future skills, IT skills and leadership skills and a variety of meanings such as soft-skills, transferable skills, interactional skills, problem solving skills, social skills, IT skills, networking skills. The term skill as such has become indistinguishable from personal characteristics, traits, competences, behaviors and attitudes. Consequently, policy makers increasing insist upon the diffuse using of skills. 'Why have skill development policies become so important, other than because of economic factors? One of the main reasons is the shift from traditional and hierarchical structures towards "flat" services and more job autonomy, with the need for employees to have more relational, communicative and problem-solving soft skills. However, technological developments and organizational renewal are not the only factors that require skill renewal. Overall, the decentralization, fragmentation and individualization of structures and processes also require the decentralization and individualization of skill development and training policies. Trends towards more individualistic HRM approaches can best be seen in the field of training, where standardized training activities are increasingly replaced by tailor-made programmes and individualized coaching offers, which are more frequently based on concrete individual needs and whose main concern is the transfer of competence. Moreover, countries increasingly try to recruit, promote and reward civil servants based on specific competency and skill sets - in a competitive market. For example, the digitalization of public administration requires employees to quickly adapt to digital change. Civil Servants are needed who have the skills to address increasingly complex problems in increasingly pluralistic societies using new tools available to governments. They will need to understand the potential and risks of new technological tools, to develop skills complementary to these new tools, be comfortable in an increasingly digital workplace and using digital tools Therefore, more countries are expecting their civil servants to take a proactive approach to their jobs (OECD, 2017, 15)".

Public administrations respond to the new challenges by a destandardization and individualization of recruitment policies and the alignment and finetuning of recruitment methods to specific skills needed (OECD 2017, 76). Increasingly, this is done by the introduction of more diverse and external recruitment practices, or separate practices, for exp. for top-officials. Moreover, different public administrations increasingly design specific competency profiles for different categories of employees. However, this trend towards different competency expectations, skill development ability and self-reliance on skill adaptation marks a clear departure from the traditional view of the compliant bureaucrat (OECD 2017, 61) and standardized recruitment policies. Today, countries wish to develop employment policies and recruitment frameworks that are driven by individual qualities, skills and expertise (OECD 2017, 10) in order to match new skill requirements and competency developments. All these trends challenge the fairness und merit-based recruitment, promotion and reward-based systems and raise the question how individual skills - under decentralized and individualized conditions - are designed, evaluated and assessed (OECD 2017, 67). At present, destandardized recruitment systems are more vulnerable to integrity violations 
than standardised systems. During the last years, especially the decentralized and destandardized central European civil services have been increasingly politicized and polarized.

\section{The effects of change}

As long ago as 2000, Paine published 'Does Ethics Pay?' and discussed the added value of ethics (Paine 2000). While evidence is indeed mounting that ethics are related to organizational performance and organizational performance to ethics, significant methodological and theoretical challenges still exist. Consequently, research is still relatively silent in this field, although it is badly needed. Methodologically, there is no consensus regarding which practices constitute a theoretically complete set of ethics policies, how to conceptually categorize these practices; the definition of ethical performance, the link between ethics and organizational costs/benefits, discussions on the effectiveness of incentives; or how ethics and ethical leadership are to be measured. Theoretically, there is still no consensus regarding the mechanism by which ethics might impact on outcomes. For example, in the field of public management, sound empirical knowledge exists only as regards the positive link between meritocratic structures and lower levels of corruption and politicization. Therefore, more empirical studies and more non-ideological deliberations in the field of ethics are badly needed if we are to better understand ethical promises, challenges and limitations. One of this challenge is to understand how Government and HR policies are changing and how this impact on ethics and workplace behavior.

Strangely enough, the interest in the link between HRM and ethics has not kept pace with the increase of interest in business ethics. Surprisingly, there is very little research on the link between HRM and ethics. Given the many initiatives in the field of managerial ethics, corporate social responsibility and company ethics, one might expect a similar growth of interest in the field of Civil Service reform, HRM and ethics, too. "After all an extremely important component of making business more ethical is to take seriously the ethical aspects of managing people" (Pinnington et al. 2012: 2). As we will see later, bringing ethical awareness into public policies and HR policies is even more important given the recent Governance and HR trends towards more destandardized and individualized HR approaches. These trends place additional burdens on managers and the need for ethical leadership.

After all, ethical challenges abound in HRM. Each day, HR managers and leaders "change, shape, redirect, and fundamentally alter the course of other people's lives" (Margolis et al. 2012, 237). Failures and successes in carrying out these tasks have an important impact on workplace behavior, fairness perception, job engagement and performance.

Of course, the question where do all civil service and HR changes lead to? is difficult to answer: The question of what has resulted from the many reforms is obviously a fundamental one. Yet it is not at all simple. Experts have no clear understanding of how public administration is changing. There is also little evidence as to whether change processes produce better results; and if so, which change processes and which reform instruments? Unfortunately, the field of civil service reform

is loaded with theories that reflect personal opinions, images and perceptions. To avoid making 
ideological or personal judgments about the effects of reforms it may be wiser to start from a general point of view to which the outcomes of civil service- and HR reforms can be positive and/or negative, effective and/or ineffective, but they may also produce a number of unintentional positive and negative side-effects, such as more bureaucracy, higher stress levels, more job intensity, less job control, higher leadership skill expectations, more ethical challenges, conflicts of interests etc. Thus, the difficulty seems to be to accept that current reforms have various reform effects at the same time.

Moreover, effects of reforms depend on many variables such as of budgetary constraints leadership developments, skills, perception of organizational justice, organizational culture and institutional configurations. In "Organizing Leviathan" (2018) Dahlström and Lapuente show that systems that are based on merit have lower levels of corruption and higher levels of government effectiveness. Despite the fact, that merit is an important element of bureaucratic systems, bureaucratic systems have no positive effect. However, concepts of "merit" are also changing. Paradoxically, the more the concept of meritocracy has become a reality, the more it seems to legitimate a hierarchy of privilege. The dilemma with the principle of meritocracy lies with the problem that our systems which reward talented people leave no hiding place for those who fail in the competitive struggle. Thus, the consequent application of the merit principle seems to undermine one of the most important foundations of the national public administrations: the principles of fairness, equality and equity. In their publication, Diploma Democracy - On the Tensions between Meritocracy and Democracy, Bovens and Wille (2009) show that Plato's ideal of the state which is run by the best and the brightest has (almost) become a reality.

Merit, as the basis for employment decisions, is one of the core values. Yet employee faith in the application of merit principle appears to be in decline in many countries because of increasing levels of corruption and politicization. A further serious deficiency is the absence of discourse on how the implementation of the merit principle in the civil services do not do justice to the increasing differences in pay, status, reward and power. Another problem is that the principle of meritocracy is increasingly self-defeating, "The more opportunity there is for people to succeed in society, the less value such success is likely to have for them" (Dench, 2006). If all people invest in more and better education and invest in their competences and skills, the process ends as a race to the top. Everybody is likely to become disappointed quickly. "If there is one thing worse than being blocked, it is seeing others succeed where you have failed" (Dench, 2006: 190). At least from these points of view, the new civil services are not necessarily fairer than the traditional structures.

Parallel to this, perceptions of organizational injustice and requests for individual recognition and feedback are gaining in importance. Experts in the field of organizational justice (Molina/Cropanzano/Martinez-Tur 2017), often make a distinction between distributive justice, procedural justice and interactional justice. As such, the importance of injustice perceptions is not new. Already in the $18^{\text {th }}$ century Immanuel Kant concluded that nothing causes more indignation than injustice. However, today, perceptions of increasing levels of inequality correlate with increasing perceptions of lack of recognition of "identity" and higher expectations that people want 
to be recognized. Fukuyama claims that indignation and perceptions of injustice are mostly caused by a lack of recognition (Fukuyama 2018). In fact, it seems that the demand for identity, diversity and recognition is also increasing in the field of HRM. Increasingly, people are attentive to the justice of events and situations in their everyday lives across a variety of contexts and to various actions and decisions made by organizations and their leaders every day. Unjust and unfair treatment and the perception of a lack of recognition can strongly influence the individual behavior and may exert a good or bad impact on individual and organizational performance.

\section{Conclusions}

If Governments want engaged, satisfied and ethical employees they must accept that "employee engagement is best seen as an outcome of managerial activity to build perceptions of trust, fairness and organizational justice, especially procedural and interactional or interpersonal justice. These are the antecedents of engagement. The question remains on how trust, fairness and justice are built. Each are essentially processes of the quality of interactions between management and employees" (Purcell, 2012:13). Unfortunately, reforms in times of budgetary constraints have led to lower levels of trust in leadership, less job satisfaction, higher levels of stress, more inequality in working conditions, fragmentation of approaches and working conditions and increasing perceptions of organizational unfairness.

Still, presently government employment systems are corresponding better to a Rawlsian principle of justice than current trends in the private sector which produce many forms of injustice and sometimes perverse results about the rewarding of individual performance. However, future civil service reform is becoming more paradoxical. Whereas in former bureaucratic times, it was believed that everybody should be treated in the same way to be fair. Today, most people believe that people should be treated differently to be fair (Cooper, 2006 53).

At present, all discussed trends challenge the classical arguments for a specific civil service and the traditional link between Government, Civil services and Ethics. Despite this, there are reasons to expect that, also in the future, civil service policies and public HR policies will continue to apply some specific bureaucratic features that will remain in place to sustain the principle of rationality, separation between the public and private sector and to defend core democratic values like equality, fairness and legal security. No other institutional actor can combine expertise, continuity in office, professionalism with impartiality and fairness. Because of this, the $21^{\text {st }}$-century needs civil services and civil servants more than ever - but in different contexts (Raadschelders/Toonen/Van der Meer 2015, 369).

Cross References: Comparative Governance, Administrative Reform, Human Resource Management, Ethics and Governance, Ethics in Public Administration and Government, Public Integrity 


\section{References}

Bazerman, M.H./ Tenbrunsel, A.E. (2011), Blind Spots, Princeton University Press

Bekke, H.A.G.M/van der Meer, F.M. (eds.) (2001), Civil Service Systems in Western Europe, Cheltenham: Edward Elgar

Bezes, P. \& Jeannot, G. (2018), Autonomy and managerial reforms in Europe: Let or make public managers manage? in Public Administration, No 96, pp. 3-22

Bovens, M. \& Wille, A. (2009), Diploma Democracy - On the Tensions between Meritocracy and Democracy, Utrecht/Leiden.

Budd, J.W \& Scoville, J.G. (2005), The ethics of human resources and industrial relations, Champaign: ILR Press

Cooper, T.L. (2006), The Responsible Administrator, $5^{\text {th }}$ edition. San Francisco: Jossey Bass.

Dahlström, C. \& Lapuente, V. \& Teorell, J. (2012), The Merit of Meritocratization: Politics, Bureaucracy, and the Institutional Deterrents of Corruption. In Political Research Quarterly, Vol. 65(3).

Dahlström, C. \& Lapuente, V., (2017), Organizing Leviathan, Cambridge University Press

Dench, G. (editor) (2006), The rise and rise of Meritocracy, Oxford: Blackwell.

European Foundation for the Improvement of Living and Working Conditions (2009), Working Conditions in the European Union, Work Organisation, Dublin: Eurofound.

Fukuyama, F., (2018), Identity, Profile Books, London

Godard, J. (2014), The psychologisation of employment relations? In Human Ressource Management Journal, Vol. 24., pp.1-18

Greenwood, J. \& Freeman, R.E. (2011), Ethics and HRM: The contribution of stakeholder theory in Business and Professional Ethics Journal, No. 30, pp. 269-292

Greenwood, M. (2013), Ethical Analysis of HRM: A Review and Research Agenda in: Journal of Business Ethics, Vol. 114, pp. 355-366 
Gruman, J. \& Saks, A.M. (2011), Performance Management and employee engagement. In Human Resource Management Review, Vol. 21., pp. 123-136

Guest, D. (2014). Employee engagement: a sceptical analysis. In Journal of Organisational Effectiveness, People and Performance, Vol. 1, No. 2.2014, pp.141-156.

Huberts, L. (2014), The Integrity of Governance, London: Palgrave Macmillan

Karam, E.P. et al. 2019, Illuminating the "Face" of Justice: A Meta-Analytic Examination of Leadership and Organizational Justice. In Journal of Management Studies, 56: 1, January 2019 doi: 10.1111/joms.12402

Kopecky, P./Meyer-Sahling, J./Panizza, F./Schuster, G. /Spirova, M. 2016, Party patronage in contemporary democracies: Results from an expert survey in 22 countries from five regions. In European Journal of Political Research, No. 55(2), 416-431

Merton, R. (1936), The Unanticipated Consequences of Purposive Social Action. In American Sociological Review, Vol. 1, Issue 6.1936, p. 896

Meyer-Sahling, J./Mikkelsen, K. (2016), Civil Service, Merit, Politicization, and Corruption: The Perspective of Public officials from five East European Countries. In: Public Administration, No. 94(4), 1105-1123

Molina, C./Cropanzano, R./Martinez-Tur, V. (2017), Organizational Justice, New York, Routledge, pp. 137-160

Mungiu-Pippidi, A. (2016), The Quest for Good Governance, Cambridge, Cambridge University Press

OECD (2017), Skills for a High Performing Civil Service, Paris, OECD

OECD (2017b), Governance at a Glance, Paris, OECD

OECD (2018), Behavioural Insights for Public Integrity, Paris. OECD

Paine, L.S. (2000). Does Ethics Pay? Business Ethics Quarterly, Vol. 10, No. 1, pp. 319-330.

Peters, G. \& Pierre, J. (eds.) (1995), Handbook of Public Administration, 1st edition, Thousand Oaks: Sage Publisher. 
Peters, G. \& Pierre, J. (Editors) (2003), Handbook of Public Administration, Second edition. Thousand Oaks: Sage Publisher.

Pinnington, A./Macklin, R./Campbell, T. Introduction: Ethical human resource management, in: Pinnington, A./Macklin, R. and Campbell, T. (eds.) (2007), Human Resource Management, Ethics and Employment, Oxford: Oxford University Press

Purcell, J. (2012), The limits and possibilities of employee engagement, Warwick Papers In Industrial Relations, Warwick: University of Warwick, No. 96

Purcell, J. (2014). Disengaging from engagement. In: Human Resource Management Journal, Vol. 24, No. 3, pp.241-254.

Raadschelders, J./Toonen, T. \& Van der Meer, F., Civil Servants in the Enabling Framework State oft he $21^{\text {st }}$ Century, in: Van der Meer, F./Raadschelders, J./Toonen, T. (eds.) (2015), Comparative Civil Service Systems in the $21^{\text {st }}$ Century, Palgrave MacMillann, Second Edition

Rauch, J. \& Evans, P. (2000). Bureaucratic Structure and Bureaucratic Performance in Less Developed Countries. In Journal of Public Economics, Vol. 75., pp.49-71.

Thompson, D.F. (1985). The Possibility of Administrative Ethics. In Public Administration Review, Vol. 45, No. 5, pp. 555-561.

Thompson, P. (2011). The Trouble with HRM. In Human Resource Management Journal, Vol 21, No 4.2011, p.363.

Thompson, P./Harley, B. (2007). HRM and the Worker. Peter Boxall/John Purcell/Patrick Wright. In The Oxford Handbook of Human Resource Management, Oxford: Oxford Press.

Vie, O.E. (2010). Have post-bureaucratic changes occurred in managerial work? In European Management Journal, Vol. 28.pp.182-194

Van der Wal, Z./Huberts, L./Van den Heuvel, H./Kolthoff, E. 2007, Central Values of Government and Business: differences, similarities, and conflicts. In Public Administration Quarterly 30 (3): 314-364. 